\title{
Considerações em Torno da Administração Direta e Indireta do Distrito Federal
}

Emmanuel F. Mendes Lyrio

Primeiro Subprocurador-Geral do Distrito Federal

SUMÁRIO: 1) Funções do Estado; 2) Organização administrativa brasileira - Centralização e Descentralização; 3) Organização Administrativa do Distrito Federal: a) Distrito Federal Unidade Federativa; b) Centralização e Descentralização.

\section{FUNÇÕES DO ESTADO}

A execução pelo Estado moderno de suas atividades, o estabelecimento e a conservação da ordem jurídica, bem como a prestação de serviços públicos, exige um sistema estrutural composto de órgãos independentes e harmônicos aos quais correspondam funções distintas.

Nos Estados primitivos o poder político concentra-se em uma só pessoa ou em um só órgão. No entanto, à medida que se desenvolviam e o progresso tornava mais complexas as relações entre a autoridade e os governados, indispensável se fez a repartição de atribuições que são deferidas a pessoas ou órgãos, contingência de um fenômeno natural, origem da especialização das funções ou da divisão de poderes.

Aristóteles na "Política" já expunha a diferenciação dos órgãos e funções: a assembléia dos cidadãos, com a competência de deliberação; a magistratura, composta de funcionários para o desempenho de tarefas administrativas; e o judiciário, para julgar conflitos de interesse. Na tripartição sugerida pelo filósofo grego a assembléia é o poder soberano. Apesar de clas- 
sificar os órgãos do poder, no entanto, as suas atribuições não são suficientemente bem delineadas, sendo delegadas pela assembléia.

Mas, foram Locke e Montesquieu que em bases jurídicas elaboraram a teoria da divisão dos poderes. Locke propondo a quatripartição de poderes: o legislativo, o executivo, o confederativo ou das relações internacionais e o discricionário (atribuições extraordinárias). Entretanto, a teoria da divisão dos poderes completou-se e desenvolveu-se pelo autor do "Espírito das Leis", vindo a constituir-se em princípio fundamental na organização dos Estados modernos. "Em todo Estado", ensina Montesquieu, "há três espécies de poderes, o poder legislativo, o poder executivo das coisas que dependem do direito das gentes, e o poder executivo das que dependem do direito civil. Pelo primeiro, o príncipe ou magistrado faz leis para algum tempo ou para sempre, e corrige ou ab-roga as que estão feitas. Pelo segundo ele faz a paz ou a guerra, envia e recebe embaixadas, estabelece a ordem, prevê as invasões. Pelo terceiro, pune os crimes e julga os dissídios dos particulares. Chama-se a última Estado". 1 julgar e a outra simplesmente o poder executivo do

Após estabelecer a distinção entre os poderes ou funções do Estado, o célebre autor justifica a necessidade da sua separação: "A liberdade política somente existe nos governos moderados. Mas nem sempre ela existe nos governos moderados. Só existe quando não se abusa do poder, mas é uma experiência eterna que todo homem que detém o poder é levado a dele abusar e vai até onde encontra limites. Quem o diria? A própria virtude precisa de limites. Para que não se abuse do poder é necessário que pela disposição das coisas, o poder limite 0
poder. Quando, na mesma pessoa ou no mesmo corpo de magis-
trados, o poder legislativo está unido ao poder executivo, não há liberdade, pois é de esperar que o mesmo monarca ou assembléia faça leis tirânicas e as execute tiranicamente. Não há também liberdade, se o poder de julgar não está separado do poder legislativo e do executivo. Se aquele estiver unido ao po-
der legislativo, o poder sobre a vida e a liberade dos cidadãos

1) MONTESQUIEU - Espirito das Leis.

R. Serv. públ., Brasilia, 108 (3) set./dez. 1973 
será arbitrário, pois o juiz será também legislador. Se o poder de julgar estiver unido ao poder executivo, o juiz terá a força de um opressor. Tudo estará perdido se o mesmo homem ou a mesma assembléia de notáveis, ou de nobres ou do povo exerce os três poderes, o de fazer as leis, o de executar as resoluções e o de julgar os crimes ou dissídios dos particulares." 2

A separação dos poderes consagra uma maior garantia à liberdade dos cidadãos, do que o sistema nos quais os poderes não se exercem diferenciadamente.

No entanto, modernamente, o sistema de repartição de poderes, no qual cada função é exercida por um órgão específico, não permite a separação absoluta, como pretendiam os políticos e filósofos da Revolução Francesa, mas atua de acordo com o princípio de harmonia e delimitação recíproca dos poderes sob uma coordenação entre os órgãos, a fim de facilitar ao Estado o desempenho de suas atividades. É o sistema de pesos e contrapesos constitucionais em que a autoridade de cada órgão é contrabalançada pela autoridade dos outros.

A função executiva, mais propriamente denominada pelos tratadistas contemporâneos função administrativa, bem como as funções jurisdicional e legislativa, não se confundem, apesar de muitas vezes não serem exercidas pelo órgão peculiar, pois tanto o órgão executivo quanto o legislativo e o judiciário, excepcionalmente, no desempenho de suas atribuições, praticam atos que, pela sua natureza, não são privativos de suas competências. É o que ocorre, por exemplo, quando o poder legislativo nomeia ou demite funcionários, exercendo, assim, função administrativa, e pratica ação jurisdicional ao julgar o Presidente da República, Ministros de Estados e outras autoridades, na forma do disposto no art. 42, n. $^{\circ}$ I e II, da Constituição Federal. Da mesma forma acontece com o Executivo e o Judiciário, quando indistintamente exercem funções administrativas, legislativas ou jurisdicionais.

A soma dessas funções governamentais compõe a administração pública entendida em sua acepção mais ampla. Tanto 0 ato de editar as leis, quanto o de aplicá-las, ou, ainda, o de

2) Idem, Ibidem. 
tutelar as relações jurídicas, tendo em vista o fim a que se destinam, o bem-estar da coletividade, constituem atividades de administração. No entanto, a tendência moderna no sentido da melhor distinção dos órgãos do Estado tem consagrado a idéia da separação dos atos peculiares das funções legislativa e jurisdicional, caracterizando-se as demais funções do Estado no elenco das funções executivas. Nesta linha de pensamento por exclusão encontram-se FRITZ FLEINER, OTTO MAYER, JELLINEK, WALINE, BRANDÃO CAVALCANTI, HELY LOPES MEIRELLES, entre outros.

Para alcançarmos o objetivo a que se propõe este trabalho, a organização administrativa do Distrito Federal, não poderemos deixar de realçar as funções do poder executivo, ou mais propriamente denominadas funções administrativas. Não nos preocuparemos em examinar as distinções entre funções políticas ou de governo, e funções administrativas correspondentes ao poder executivo, como querem BIELSA e RANELLETTI. Tal diferenciação não tem sido precisamente definida, ensinando ALEXANDRE GROPALLI que a mesma "não pode ser fixada de modo nítido e preciso e é difícil verificar onde acaba uma e começa a outra; e que isso é assim, confirma-o indiretamente a própria insuficiência dos critérios de discernimento propostos pela doutrina." 3

A irrelevância da diferenciação do conceito de atos políticos e de atos administrativos no estudo da organização dos serviços públicos, através dos quais atua o Estado, leva-nos a abandonar a questão para examinarmos as formas e os meios do exercício das atribuições administrativas, cuja importância é realçada por CINO VITTA, ao dizer que para a ação administrativa "não há trégua, nem de hora, nem de minuto." 4

\section{ORGANIZAÇÃO ADMINISTRATIVA BRASILEIRA}

Centralização e Descentralização

Para prevenir possíveis conflitos de competência entre os órgãos no exercício de suas atribuições conveniente a existência de uma divisão administrativa coincidente com a forma de governo e a organização política do Estado.

3) ALEXANDRE GROPALLI - Doutrina do Estado.

4) CINO VITTA - Diritto Amministrativo.

R. Serv. públ., Brasília, 108 (3) set./dez. 1973 
Definido o Estado brasileiro como uma República Federativa sob um Governo presidencialista e democrático (CF, Arts. 1. e 73), possuindo os Estados-membros autonomia político-administrativa, deverá a sua administração organizar-se coincidentemente com estes princípios constitucionais. Esta autonomia assegurada rigidamente pelo nosso direito constitucional (CF, arts. 13 e 15), é o que caracteriza a descentralização territorial das funções do Estado Federal.

A forma federativa de governo permite organizar o Estado de acordo com uma estrutura politicamente descentralizada, através da distribuição de competências, mitigadamente controladas pela União, usando a denominação do nosso direito positivo, na qual se assenta a soberania.

No entanto, em face do objetivo a que nos propomos, não nos deteremos na distinção dos sistemas centralizados e descentralizados do poder político, analisando o Estado federal brasileiro na sua gênese constitucional, mas apenas tentaremos demonstrar o processamento dos sistemas centralizados e descentralizados meramente administrativos ou de administração material dos serviços públicos, "planos que se superpõem mas não se confundem", no ensinamento de CAIO TÁCITO. ${ }^{5}$

O desenvolvimento do país, a industrialização, o progresso da técnica, a formação de uma cultura brasileira através de pensamento e fórmulas forjadas dentro da nossa realidade social para solução dos problemas brasileiros, exigiu a ampliação dos instrumentos de execução das atividades do Estado, de modo a possibilitar a sua ação governamental, no atendimento das necessidades essenciais ou secundárias da comunidade nacional. É o surgimento no Brasil do fenômeno da descentraliZação das atribuições administrativas, não só na esfera federal, mas como afirmação dos anseios locais, em consonância com o sistema federativo, ideal republicano, proclamado pela Constituição de 1891. A organização centrípeta a que se submetem os Estados-membros brasileiros não se contrapõe ao princípio federativo da auto-administração dos serviços públicos regionais. A impotência ou a incapacidade da administração direta, composta de uma estrutura rudimentar, cuja classificação é exposta por MAX FLEIUSS, na sua "História Administrativa do

5) CAlO TÁCITO - Contribuiçăo à Reforma Administrativa e Judiciária. 
Brasil", urgia a criação de órgãos adequados que desemperrassem a vida administrativa brasileira, alterando a fisionomia do Estado que passou, assim, a possuir um corolário mais extenso de obrigações no complexo social.

OSCAR SARAIVA observando esta modificação de comportamento, explica: "As transformações mundiais, operadas por força das conseqüências da Primeira Grande Guerra e talvez mais pelos processos da técnica e dos meios de produção, reagiram profundamente sobre a vida de todos os Estados. De um lado, os excessos de produção, de outro lado a falta de mercados, esse desequilíbrio veio repercutir sobre a administração estatal. Em outro setor, o progresso da legislação social exigindo a proteção do trabalhador não só em suas relações com os respectivos empregadores (Legislação do Trabalho), mas ainda em seu bem-estar social (Assistência e Previdência), esse progresso veio colocar o Estado a braços com outras questões. O problema da segurança exterior complicou-se com a defesa dos mercados exteriores e o da ordem interna com a garantia do bem-estar social em seus múltiplos aspectos. O Estado deixou de ser o que era, Estado puramente político, para transformar-se em Estado político, Estado econômico, Estado social, um aspecto reagindo sobre outro e todos influindo de modo capital na luta pela existência organizada e independente." 6

Na fase do Estado social de Direito ou Estado Providência, último estádio da evolução estatal, conforme as etapas sugeridas por GABINO FRAGA, ${ }^{7}$ a organização administrativa brasileira realiza-se em duas linhas, horizontal e vertical. Em sentido horizontal, a organização político-administrativa, a descentralização territorial: União, Estados e Municípios; em sentido vertical, a estrutura administrativa: institucional ou orgânica.

Ainda lembrando a lição de CAIO TÁCITO: "A divisão institucional ou orgânica tem, como pressupostos, a eficiência técnica e a especialização funcional, atendendo a razões pragmáticas. A luz de tais critérios de conveniência, fica livre ao legisministrativa." 8

6) OSCAR SARAIVA - As Autarquias no Direito Público Brasileiro.
7) GABINO FRAGA - Derecho Administrativo.
8) CAIO TACITO - ob. cit.

R. Serv. públ., Brasília, 108 (3) set./dez. 1973 
No Brasil a transferência das funções administrativas, excluídas algumas concessões de serviços públicos, tais como fornecimento de energia elétrica, gás, comunicações e transportes, começaram a efetivar-se com o "Estado Novo", em decorrência da modificação da estrutura econômica do nosso país, partindo para o tipo de economia industrial. Anteriormente, eram por demais modestas as instituições administrativas, reflexo da estrutura social rudimentar assentada na produção rural. Daí 0 aparecimento de entes dotados de personalidade jurídica própria, criados para o desempenho de tarefas do Estado, desafogando a administração pública centralizada, que se exercia através de órgãos subordinados, as repartições públicas.

É a administração indireta ou descentralizada em que a execução das atividades típicas ou atípicas do Estado são delegadas a pessoas administrativas autônomas, com patrimônio próprio, maior autonomia administrativa e maior poder de decisão em relação aos órgãos ou repartições subordinados. Estes entes autônomos podem reger-se pelas normas de direito público ou de direito privado. Discorrendo sobre a matéria, é ainda CAIO TÁCITO quem escreve: “A criação, pelo leegislador ordinário, de pessoas administrativas autônomas, exprime-se, fundamentalmente, sob duas tendências distintas. De uma parte, a lei cria uma nova pessoa jurídica de direito público, de prerrogativas equivalentes às da administração direta, destinada, de modo específico, a um fim especial, ocorre, em outros casos, a recepção no Direito Administrativo, de formas de pessoas jurídicas de direito privado, às quais o legislador atribui encargos administrativos, de natureza comercial, industrial, cultural e assistencial." 9

Em nossa organização administrativa foram as autarquias as primeiras entidades constituídas para colaborar na maior racionalização e especialização dos serviços públicos, mediante delegação de competência, conforme lição do notável professor argentino RAFAEL BIELSA, que assim se expressa. "Os fins de uma entidade autárquica são o desempenho de funções de caráter público, isto é, funções do Estado (em sentido lato)." 10

O conceito dos entes autárquicos tem sido motivo de larga polêmica doutrinária, tanto no que concerne às suas modalidades, consideradas suas esferas de atuação ou de competência,

9) IDEM - ob. cit.

10) RAFAEL BIELSA - L'autarquia de las universidades. 
veja-se as classificações propostas por ERYMÁ CARNEIRO ${ }^{11}$, BRANDÃO CAVALCANTI ${ }^{12}$, OSCAR SARAIVA ${ }^{13}$, ou quanto às distinções de espécies de autarquias pelas formas jurídicas de suas constituições. Entre os que adotam este último critério, encontra-se o professor de São Paulo CELSO ANTONIO BANDEIRA DE MELLO: "Classificar as autarquias pelo campo de atuação em que se inserem nada diz sobre sua estrutura jurídica nem fornece noções básicas de valor significativo, sobre o regime normativo delas. Saber, por exemplo, que uma autarquia é previdenciária e não creditícia, pouca ou nenhuma notícia traz sobre sua estrutura fundamental, enquanto pessoa jurídica, e, da mesma forma, pouco ou nada revela sobre a disciplina normativa que preside suas relações internas e externas". "As espécies jurídicas que se pudessem discernir, seriam, pois, verbi gratia - a título de hipótese imaginosa - a das autarquias sujeitas a estrito controle de tutela e as submetidas a controle mais suave; a das autarquias cujos servidores fossem assemelhados aos funcionários públicos e a das entidades cujos servidores se regessem por legislação especial ou trabalhista; as que dispõem de acentuado poder de imperium e as que o tem muito abrandado, e assim por diante." 14

No entanto, pelo fato de as autarquias não haverem surtido o efeito desejado, produzindo o que ALIM PEDRO chamou de "desautarquização das autarquias", 15 sucedeu a criação de novas formas de administração: sociedades de economia mista, empresas públicas e as fundações instituídas pelo poder público.

Necessita, contudo, observar que a entidade autárquica voltou a ser nos últimos anos examinada pelos técnicos da reforma administrativa, no sentido de um processo de "reautarquização", gerando a sua inclusão nos órgãos integrantes da administração indireta e a sua conceituação legal, conforme veremos mais adiante. A ausência por longo período de um sistema legislativo da administração indireta dificultou a compreensão da exata noção dos entes autárquicos e paraestatais (sociedades de economia mista e empresas públicas) que se formavam de acordo com as circunstâncias momentâneas e as formula-
ções doutrinárias.

\footnotetext{
11) ERYMA CARNEIRO - As autarquias e as sociedades de economia mista no Estado
Nacional.

13) OSCAR SARAIVA BRANDÃO CAVALCANTI - Teoria do Estado.

14) CEISO

Monteiro - F

15) ALIM PEDRO - Relatório - Estudo I Administraçăo.
}

R. Serv. públ., Brasília, 108 (3) set./dez. 1973 
Recentemente, porém, o Decreto-lei $n .^{\circ} 200$, de 25 de fevereiro de 1967, que fixa as diretrizes para a reforma administrativa, após estabelecer as formas de execução direta e indireta da administração (art. $4 .^{\circ}, \mathrm{n}^{\circ}$ I e II), define, no artigo $5 .^{\circ}$, n. ${ }^{\circ}$ I, II e III, a autarquia, a empresa pública e a sociedade de economia mista, ad literam:

"Para os fins desta lei, considera-se:

I - autarquia - o serviço autônomo, criado por lei, com personalidade jurídica, patrimônio e receita próprios, para executar atividades típicas da administração pública que requeiram para seu melhor funcionamento, gestão administrativa e financeira descentralizada;

II - empresa pública - entidade dotada de personalidade jurídica de direito privado, com patrimônio próprio e capital exclusivo da União, criada por lei para exploração de atividade econômica que o Governo seja levado a exercer por força de contingência ou de conveniência administrativa, podendo revestir-se de qualquer das formas admitidas em direito;

III - sociedade de economia mista - a entidade dotada de personalidade jurídica de direito privado, criada por lei para exploração de atividade econômica, sob a forma de sociedade anônima, cujas ações com direito a voto pertençam, em sua maioria, à União ou a entidade da administração indireta.

Convém lembrar que as fundações instituídas em virtude de lei federal foram excluídas da administração indireta da União, ficando, no entanto, sujeitas à supervisão ministerial de que tratam os arts. 19 e 26 do referido decreto-lei, sempre que recebam subvenções ou transferências à conta da União. A instrumentação legal da reforma administrativa que vem sendo com afã implantada pelo Governo federal, de modo a permitir a maior eficiência na execução das atividades estatais, constitui fator importantíssimo na construção de uma sociedade brasileira de novas dimensões da integração nacional e social, condição determinante para sua afirmação progressiva como nação desenvolvida.

O desempenho da administração direta, das autarquias, e
das empresas governamentais, sem, contudo, excluir o dina- 
mismo da iniciativa privada, mediante uma organização racional e moderna, sujeitas aos princípios de planejamento, coordenação, descentralização, delegação de competência e controle (Decreto-lei 200/67, art. 6..$^{\circ}$ ) ensejará a atuação eficiente do Governo, para os fins a que se propõe: o bem-estar, a democratização de oportunidades, a preservação dos valores humanos e
culturais.

\section{ORGANIZAÇÃO ADMINISTRATIVA DO DISTRITO FEDERAL Distrito Federal - Unidade Federativa}

\section{Centralização e Descentralização}

Estes os mesmos princípios que inspiraram a reforma administrativa do Distrito Federal, promulgada pela Lei 4.545 , de 10 de dezembro de 1964.

Contudo, antes de estudarmos as formas de execução dos serviços do Distrito Federal, nos permitiremos rápida incursão sobre a sua posição no Estado federativo brasileiro.

O estudo das competências do Distrito Federal dentro de um prisma metodológico, para situá-lo no Estado federativo, apesar da sua importância não mereceu o devido cuidado por parte dos constitucionalistas brasileiros.

O ilustre advogado JOSÉ PAULO SEPÚLVEDA PERTENCE, em brilhante trabalho sob o título "Contribuição à Teoria do Distrito Federal no Direito Constitucional Brasileiro", esclarece que "essa ausência, em parte, se pode atribuir à maior sedução da teoria do Estado federal em seu esquema típico: seus temas absorvem os tratadistas, deixando na penumbra a existência, na estrutura federal, das formas heterogêneas de descentralização, quais o Distrito Federal e territórios." E mais adiante: "Além do que, alguns dos melhores estudos sobre o Distrito Federal sob a Constituição passada, têm muito de sua significação científica abalada pelo seu comprometimento polêmico na discussão política da reivindicação carioca de eleger o Pre-
feito da nova capital." 16

Não poderemos aqui, mesmo que resumidamente, lembrar a evolução histórico-constitucional do Distrito Federal, as suas

16) JOSÉ PAULO SEPÚLVEDA PERTENCE

Direito Constitucional Brasileiro.

R. Serv. públ., Brasília, 108 (3) set./dez. 1973 
transformações no tocante às restrições e ampliações de competência, que se processaram desde a Constituição de 1891 até à Carta vigente como conseqüência do grau de descentralização da ordem normativa do Distrito, ora colocando-o mais próximo do Estado-membro (Constituição Federal, 1934), às vezes subordinando-o mais amplamente à ordem central (1937 até à Constituição vigente), sistema adotado pelo Constituinte de 1891. Tal estudo acha-se magnificamente exposto no trabalho acima mencionado.

A criação do Distrito Federal não é inovação do Direito Brasileiro. Veja-se os países entre os quais os Estados Unidos, Argentina e o México, cujas capitais, sede do Governo, têm a sua administração local dependente da administração central.

É entidade política ou constitucional sui generis, integrante da federação (Cf. art. $1^{\circ}$ ), não possuindo, todavia, a tipicidade dos Estados-membros, uma vez não lhe ser conferido pela ordem central o mesmo grau de descentralização destes últimos. A sua ordem local, como já observado, está em estrita dependência da ordem central, equiparando-se aos territórios pelo critério do grau de descentralização.

Enquanto ao Estado-membro é assegurada a descentralização normativa pela garantia da sua competência legislativa, no tocante aos poderes remanescentes, obstaculando a interferência do legislador ordinário da União, requisito formal essencial da federação, na concepção Kelseniana ${ }^{17}$, e característico da autonomia dos Estados federados, o Distrito Federal acha-se tutelado pela ordem central, recebendo sua competência da lei ordinária federal.

Acrescente-se, ainda, ao aspecto formal, o requisito material como elemento característico da autonomia, traduzido no poder constituinte do Estado, embora limitado pelo poder central, elemento que na expressão de KELSEN e JELLINEK é chamado de poder de "auto-organização".

Da mesma forma que ao Distrito Federal nāo é deferido o requisito formal, assim também com relação ao material. O Distrito Federal não possui a competência de auto-constituição, que permanece na esfera de competência legislativa da União e que é exercida através da lei de organização administrativa

17) VICTOR NUNES LEAL - Federaçăo. 
(CF, art. 17), só the sendo conferida diretamente pela Constituição pequena parcela de atribuições descentralizadas da ação governamental.

Embora não possuindo todas as condições essenciais componentes do Estado, o Distrito Federal ao administrar os seus serviços públicos, objeto desta análise, exerce atividades estatais dentro de um prisma puramente material, sob a forma de descentralização local.

Passemos, assim, ao exame do processamento das atividades de administração do Distrito Federal. A organização administrativa do Distrito Federal acha-se consubstanciada na Lei 3.751, de 13 de abril de 1960, Lei Orgânica do Distrito Federal, e na Lei 4.545 , de 10 de dezembro de 1964 , que dispõe sobre a sua reestruturação administrativa.

As alterações constitucionais posteriores que revogaram em parte disposições da Lei orgânica como: a competência da iniciativa das leis, retirada do Prefeito (art. $2 .^{\circ}, \mathrm{n} .^{\circ}$ IV e art. $8 .^{\circ}, \S$ $2 .^{\circ}$ Lei $n .^{\circ} 3.751 / 60$ ), e transferida para o Presidente da República (CF, art. 57, n. IV); a revogação de toda a Seção I, do Capítulo II, da Lei $3.751 / 60$, que dispõe sobre a Câmara do Distrito Federal, cujas atribuições passaram para a órbita de competência do Senado Federal (CF, art. $\left.17, \S 1 .^{\circ}\right)$, não se relacionam com o objeto desta análise que procura alcançar apenas a competência do Distrito Federal no que concerne à administração dos serviços locais, assim discriminados na sua lei de constituição:

\section{"Art. 2. - Compete ao Distrito Federal exercer to- dos os poderes e direitos que lhe são ex- plícita ou implicitamente deferidos pela Constituição e pelas leis, especialmente:}

I - Organizar os seus serviços administrativos;

IX - fazer concessões de serviços públicosos não reservados à União. 
E ainda:

"Art. 3. - Compete ao Distrito Federal, concorrentemente com a União:

I - Velar pela observância da Constituição e das Leis;

II - cuidar da saúde pública e da assistência social;

III - proteger as belezas naturais e os monumentos de valor histórico ou artístico.

"Art. 4. - Ao Distrito Federal, no desempenho da missão de promover o bem comum, incumbe:

a) - Zelar pela cidade de Brasília, pelas cidades satélites e comunidades que a envolvem, no Território do Distrito Federal;

b) - Manter serviços de amparo à maternidade, à infância, à velhice e à invalidez;

c) - organizar o seu sistema de ensino, difundir a instrução através de escolas públicas de todos os graus, e fomentar, por todos os meios ao seu alcance, o aproveitamento da cultura."

Por exclusão permanecem com a administração federal os demais serviços, que não se acham expressamente enumerados na Lei $3.751 / 60$.

A princípio singela, a administração do Distrito Federal era executada pelo Prefeito e dois Secretários-Gerais (Lei 3.751/60, arts. 19 e 46), o primeiro com as atribuições deferidas pela própria Lei Orgânica (art. 20) e os segundos pelo Decreto $n .^{\circ} 1$, de 9 de maio de 1960 , que denominava no seu artigo $1 .^{\circ}$ as Secretarias-Gerais, de Secretaria-Geral de Administração e Secretaria-Geral de Assistência, com os seguintes encargos, verbis: 

"Art. 2. - A Secretaria-Geral de Administração terá a seu cargo as atividades relativas a pes- soal, material, orçamento, contabilidade, estatística, comunicações e receita e des- pesas públicas."

"Art. 3. - A Secretaria-Geral de Assistência incumbir-se-á das atividades relativas à educação e cultura, saúde, assistência médicohospitalar, higiene pública, assistência social e educação sanitária."

A medida que crescia a cidade, originando como conseqüência a complexidade dos problemas sociais, esta estrutura primitiva ampliava-se, não podendo mais atender aos reclamos da comunidade, provocando uma enxurrada de decretos, criando e estruturando órgãos auxiliares do Poder Executivo, sob a forma de Departamentos ou de Superintendências-Gerais no fim da melhor divisão de atribuições para execução e atendimento dos serviços públicos de administração. Assim:

Decreto $n .^{\circ}$ 6, de 9.6.1960 - cria o DER;

Decreto $n .^{\circ} 15$, de 29.9.1960 - cria o Departamento de Agricuitura;

Decreto n. 19 , de 27.1.1961 - cria o Departamento de Obras;

Decreto n. 43 , de 28.3.1961 - altera a estrutura administrativa em que são criadas as Superintendências-Gerais de:

Educação e Cultura;

Agricultura e Produção;

Economia;

Segurança e Interior;

Decreto $n$. 232, de 3.4.1963 - cria a Superintendência Geral de Assistência e Serviço Social;

Decreto n. 156 , de 7.2.1962 - cria a Superintendência Geral da Fazenda.

Esta a legislação que julgamos de maior interesse relativa à organização administrativa do Distrito Federal até a promulgação da Lei que a reestruturou, e pela qual se pode observar que a administração do Distrito Federal era quase que exclusiva- 
mente exercida pelos órgãos da Administração Central, cujos dirigentes agiam mediante delegação de competência, caracterizando o que se denomina de desconcentração administrativa. No entanto, à esta época já dispunha o Distrito Federal de instrumentos para execução indireta de prestação de serviços, algumas fundações e empresas, embora subordinadas diretamente ao Prefeito e assim enumeradas:

Fundação Educacional do Distrito Federal - Decreto n. ${ }^{\circ}$ 48.297, de 17.6.1960;

Fundação Hospitalar do Distrito Federal - Decreto n. ${ }^{\circ}$ 48.298, de 17.6.1960;

Fundação Zoobotânica do Distrito Federal - Decreto n. 48.926 , de 8.9.1960;

TCB - Sociedade de Transportes Coletivos, por cotas de responsabilidade limitada, conforme Escritura Pública de 8 de maio de 1961;

SHEB - Sociedade de Habitações Econômicas de Brasília, por cotas de responsabilidade limitada, conforme Escritura Pública de 2 de março de 1962;

SAB - Sociedade de Abastecimento de Brasília, por cotas de responsabilidade limitada, conforme Escritura Pública, de 25 de maio de 1962.

Imperioso lembrar que a Companhia Urbanizadora da Nova Capital do Brasil - NOVACAP, objeto das mais diversas opiniões no tocante à sua conceituação jurídica, por quantos foram chamados a estudar situações em que a mesma fosse parte, considerada por alguns sociedade de economia mista, por outros modalidade de autarquia, ou, ainda, empresa pública, passou a integrar a administração descentralizada indireta do Distrito Federal, por força do disposto no art. 48 da Lei $n .^{\circ} 3.751 / 60$, executando serviços públicos e de utilidade pública, mediante concessão da União, em virtude da sua própria finalidade, como vemos do exposto na Lei 2.874, de 19 de setembro de 1956:

"Art. 3. - A Companhia Urbanizadora da Nova Capital do Brasil terá por objeto: ........... 
3. execução, mediante concessão, de obras e serviços da competência federal, estadual e municipal, relacionados com a nova capital;

Como espécies desses serviços o fornecimento de energia elétrica e o de telecomunicações, de competência da União (CF, art. $8 .^{\circ}, \mathrm{n} .^{\circ} \mathrm{XV}$ ).

Sentindo a inadequação desta organização estrutural em face da realidade social do Distrito, 0 insigne administrador PLINIO CANTANHEDE, no exercício do cargo de Prefeito, determinou, em 1964, estudos para uma reforma administrativa de base. Comentando a estrutura acima mencionada é o trecho da Exposição de Motivos que encaminhou o projeto transformado na Lei 4.545, de 10.12.64: "A lacuna principal dessa estrutura residia na ausência de secretarias em número mínimo compatível com a diversidade das funções do Distrito Federal. A criação de Superintendências-Gerais, espécies de secretarias de fato não supriu a falha. Em conseqüência, a Companhia Urbanizadora da Nova Capital do Brasil, que empreendeu a obra pioneira de criação da cidade, continuou a acumular as funções propriamente urbanizadoras, outras indispensáveis para assegurar a Brasília serviços públicos e serviços de utilidade pública essenciais.

Com igual relevo, sobressai a falha consistente na multiplicidade de subordinações ao Prefeito de órgãos da administração direta e unidades da administração indireta, tolhendo-lhe a capacidade de organização." 18

Propunha-se, assim, uma reforma administrativa não apenas de sentido orgânico, mas motivada por objetivos modernos e dinâmicos para dotar a administração pública de um mecanismo capaz de fazê-la acompanhar o processo de desenvolvimento sócio-econômico da capital da República. Ao lado de uma reforma orgânica, desenvolver-se-ia uma reforma funcional, elaborada cientificamente, a fim de que as formas de controle e exe-

18) PLINIO CANTANHEDE - Exposiçăo de Motivos n.o 60 - GP.

R. Serv. públ., Brasilia, 108 (3) set./dex. 1973 
cução dos serviços se exercessem mediante uma organização sistêmica, no sentido de alcançar a centralização do controle e a descentralização da execução.

Este o característico mais importante da reforma administrativa do Distrito, que precedendo a reforma administrativa federal, no entanto, à mesma se assemelha, no seu conteúdo técnico e filosófico, nos fundamentos em que se assenta, visando a valorização do homem, considerado o mais importante elemento da dinâmica administrativa, tendo em vista a maior distribuição da autoridade e, conseqüentemente, da responsabilidade.

Não poderemos, obviamente, neste trabalho, examinar a reforma administrativa do Distrito Federal em todos os seus aspectos, propondo-nos, apenas, à análise do princípio da descentralização, tocantemente à administração direta e indireta, embora, como já afirmamos, a Lei 4.545, de 10 de dezembro de 1964 , consagrou, em seus enunciados, além da descentralização, os princípios de: planejamento, coordenação, delegação de competência e controle.

O conceito de descentralização está compreendido nos conceitos de democracia e de liberdade.

A concentração da autoridade nas mãos da minoria pode ser definida como centralização e descentralização à repartição, à distribuição do poder de decisão. Por isto, a relevância do sistema de descentralização adotado pela Lei $n .^{\circ} 4.545 / 64$ e pelo Decreto-lei n. $.^{2} 20 / 67$, constituindo forte elemento de preservação da democracia, pela maior distribuição dos meios de comando, do poder administrativo.

O ex-Ministro HÉLIO BELTRÃO, tratando do tema, assim se expressa: “A descentralização não é assunto de técnica de administração, nem é, apenas, uma maneira de aumentar a eficiência da máquina administrativa. Ela tem um sentido muito mais profundo, porque está ligada aos conceitos de democracia e de liberdade." Continuando, diz o notável homem público: "E quando advogo na administração a descentralização executiva, o que estou procurando fazer é garantir a liberdade do homem dentro da administração, pois não existe realmente nada mais eficiente do que a própria liberdade. A conexão entre eficiência e liberdade é mais sólida do que possa parecer. Até hoje não se inventou 
nenhuma fórmula mágica, nenhuma técnica especial capaz de substituir, em termos de eficiência, o dinamismo do homem agindo livremente, inteligentemente, em busca da própria felicidade, em busca de sua auto-realização." 19

Razão de havermos afirmado nestas considerações constituir o homem fator essencial de qualquer reforma administrativa de maiores dimensões.

Estas as bases filosóficas da lei de reorganização administrativa do Distrito contidas nos artigos $1 .^{\circ}$ e $2 .^{\circ}$, ao incluir os órgãos de administração descentralizada:

Art. $10^{\circ}$ - A estrutura básica da administração do Distrito Federal compreende:
a) a Secretaria do Governo (SEG);
b) a Secretaria de Administração (SEA);
c) a Secretaria de Finanças (SEF);
d) a Secretaria de Educação e Cultura (SEC);
e) a Secretaria de Serviços Sociais (SSS);
f) a Secretaria de Saúde (SES);
g) a Secretaria de Viação e Obras (SVO);
h) a Secretaria de Serviços Públicos (SSP);
i) a Secretaria de Agricultura e Produção (SAP); deral:

Art. 2. - Integram ainda a administração do Distrito Fe-

a) o Gabinete do Prefeito (GAP);

b) o Conselho de Arquitetura e Urbanismo (CAU);

c) o Conselho de Desenvolvimento Econômico (CDE);

d) o Conselho de Educação do Distrito Federal;

e) outros Conselhos ou Comissões que vierem a ser criados por Lei ou por ato do Poder Executivo do Distrito Federal;

f) Vetado

g) a Procuradoria-Geral (PRG);

h) os órgãos da administração descentralizada (grifamos).

19) HÉLIO BELTRÃO - Conferência - Apud Relatório Set., 70 - Secretaria do Governo
do Distrito Federal. R. Serv. públ., Brasília, 108 (3) set./dez. 1973 
Nessa estrutura foi posteriormente incluída a Secretaria de Segurança Pública, através do Decreto-lei n. ${ }^{\circ} 315$, de 13 de março de 1967, cujas atribuições eram anteriormente exercidas pelo Serviço da Polícia Metropolitana do Departamento Federal de Segurança Pública (art. 53, Lei 3.751/60), e alterada, também, a denominação do Gabinete do Prefeito para Gabinete do Governador (Decreto n. 1.844 , de 10 de novembro de 1971) como decorrência da modificação da denominação do cargo da Autoridade Maior do Distrito (CF, art. $17, \S 2 .^{\circ}$ ).

O princípio da descentralização já adotado na sistemática da reforma administrativa do Distrito Federal, antecedentemente ao Decreto-lei n. $200 / 67$, contrapunha-se à ordem reformulada na qual competia aos escalões superiores as decisões de toda a matéria administrativa, não só sob a forma da descentralização institucional, mas, ainda, efetivando-se sob a espécie de descentralização burocrática, desconcentrando o poder administrativo dentro do próprio órgão central.

Cremos que esta técnica moderna de administração achase consubstanciada expressamente no artigo 14 da lei número 4.545/64:

"Art. 14 - Ressalvados os casos de competência privativa, expressa em Lei e as exceções estabelecidas pelos dirigentes de órgãos diretamente subordinados ao Prefeito, as decisões, em primeira instância, caberão aos dirigentes de nível departamental, aos dirigentes dos órgãos relativamente autônomos e aos administradores regionais.

Parágrafo único - A competência de que trata este artigo será delegada, sempre que possível, aos órgãos ou serviços incumbidos do contato direto com o público."

É a descentralização no serviço das atividades auxiliares de administração, mediante delegação de competência, aquelas não definidas nas atividades-fim do Distrito, a prestação dos serviços públicos. Estas atividades que se constituem em objetivos do Governo são executadas não só pelo poder central, mas pela administração descentralizada, nos termos do artigo $3 .^{\circ}$ da Lei n. 4.545/64: 
"Art. 3. - A administração descentralizada da Prefeitura do Distrito Federal compreende:

I - Sem personalidade jurídica:
a) as Administrações Regionais;
b) os Serviços ou estabelecimentos relativamente autônomos.

II - Com personalidade jurídica:

as autarquias, empresas ou fundações instituídas por ato do Poder Público.

$\S 10^{\circ}$ - Cada um dos órgãos que integram a administração descentralizada fica obrigatoriamente sujeito à supervisão e controle da Secretaria interessada em sua principal atividade, sem prejuízo da auditoria financeira, a cargo do órgão próprio da Secretaria de Finanças.

$\S 2 .^{\circ}$ - Os assuntos de interesse dos órgãos da Administração serão sempre encaminhados através da Secretaria incumbida da supervisão e controle do órgão, na forma deste artigo."

Assim temos a administração direta descentralizada e a administração indireta. Os órgãos relativamente autônomos e as administrações regionais, conforme delegação de competência (artigo 14, parágrafo único da Lei n. $4.545 / 64$ ) e, as autarquias, empresas públicas, sociedades de economia mista e fundações com personalidade jurídica, sujeitos, porém, às normas de supervisão e controle, princípios salutares para o equilíbrio entre a administração centralizada e descentralizada, permitindo o acompanhamento da execução dos serviços no sentido da correção e a uniformidade da ação governamental em relação às normas, e ao planejamento global.

As administrações regionais e os órgãos relativamente autônomos definidos nos artigos $9 . \circ 10,11$ e 12 , compreendendo os primeiros os órgãos locais, as regiões administrativas: Brasília, Gama, Taguatinga, Brazlândia, Sobradinho, Planaltina, Jardim e Paranoá; e os segundos aqueles que pela natureza de suas atribuições, industriais ou comerciais, necessitam de maior "flexibilidade administrativa e financeira", tais como: R. Serv. públ., Brasília, 108 (3) set./dez. 1973 
Serviço de Limpeza Urbana, Administração da Estação Rodoviária, Departamento de Educação Física, Esportes e Recreação e Departamento de Turismo.

A Administração Indireta, no entender dos estudiosos da ciência da Administração e do Direito Administrativo, é uma forma evoluída de descentralização por serviços do Estado-Ação pluridimensional, caracterizando-se sob um prisma técnico pela natureza da especialização dos serviços, e sob um aspecto jurídico quanto à personalidade jurídica e patrimônio próprios, e maior autonomia administrativa. São no Distrito Federal: as autarquias, empresas públicas, sociedades de economia mista e fundações.

CAIO TACITO, o notável jurista, com a precisão e felicidade de expressão que lhe é peculiar, escreve: "Podemos, em suma, comparar as modernas administrações públicas a um sistema planetário, no qual as pessoas jurídicas componentes da administração descentralizada gravitam em torno ao núcleo central da administração direta." 20

Assim o complexo administrativo do Distrito, composto de órgãos dotados de autonomia, constitui um sistema de massas administrativas em que o Executivo é o centro gravitacional de onde parte a força impulsionadora da ação estatal.

Grande a preocupação dos autores ao tratarem dos meios usados pelo Estado na ânsia de satisfazer aos reclamos dos governados, à busca eterna pelo homem da felicidade, redundando no seu desdobramento, na sua pluralização, sem, contudo, abalar a sua unidade. No entanto, a diversificação dos entes autônomos gerou diversas correntes de opiniões quanto às suas características e conceituações. A verdade é que entes autônomos, pessoas administrativas, estabelecimentos públicos, entidades paraestatais e autarquias são na lição de FRANCISCO CAMPOS"... combinação de meios financeiros e jurídicos, um agenciamento ou uma técnica, um método ou um processo de distribuição ou de repartição da competência do Estado. Público continua a ser o serviço, públicos os poderes utilizados na sua gestão, de direito público e competência outorgada ao ente autônomo ao instituto ou a instituição. Do ponto de vista da ordem jurídica, ainda que a competência do ente autônomo seja na aparência exercida como um direito próprio, é apenas uma com-

20) CAIO TACITO - ob. cit. 
petência delegada, da mesma natureza que o é a competência de um órgão da administração centralizada." 21

Ademais, o Decreto-lei $n .^{\circ} 200$, de 25.2.1967, não permite dúvidas quanto à distinção entre autarquias, empresas públicas e sociedades de economia mista, definindo-as no artigo $5 .^{\circ}$, como transcrito nas notas sobre a organização administrativa federal.

Já observamos que os entes autônomos podem dividir-se quanto à sua natureza em dois grandes grupos: de direito público e de direito privado. Os primeiros são os entes estatais, as autarquias; e os segundos, entidades paraestatais, as empresas públicas e as sociedades de economia mista.

"As autarquias," na definição de HELY LOPES MEIRELLES, "são órgãos autônomos da administração, criados por lei, com personalidade jurídica de direito público, patrimônio próprios e atribuições estatais específicas." 22 Como vemos, as funções das autarquias são típicas, são inerentes à própria essência do Estado.

CARVALHO SANTOS, comentando o artigo $319, \S 2 .^{\circ}$ do Código de Processo Civil, revogado pela Lei $n .^{\circ} 1.533$, de .... 31.12.1951, ensina: "Por estabelecimentos públicos, convém acentuar de início, devem entender-se as denominadas autarquias administrativas, sinonímia autorizada pela doutrina (cfr. Tito Prates da Fonseca, Direito Administrativo). As autarquias administrativas exercem funções de Estado. Daí já se pode concluir que a autarquia administrativa não é senão uma pessoa interposta, de direito público, por meio da qual o Estado exerce a administração pública, em determinado setor." 23

A distinção entre as autarquias e as entidades paraestatais reside no fato de que enquanto naquelas a atividade de gestão e interesses públicos são próprios do Estado, nestas últimas a sua atividade tem caráter privado, que, embora indiretamente, podem satisfazer o interesse da coletividade, colaborando com o Estado, em face dos objetivos para as quais foram constituídas. Anote-se, ainda, a imunidade tributária deferida pela Constitução Federal (Art. 19, $\S 10^{\circ}$ ) às autarquias "no que se refere

21) FRANCISCO CAMPOS - Direito Administrativo.

22) HELY LOPES MEIRELLES - Autarquias e Entidades Paraestatais.

23) CARVALHO SANTOS - Código de Processo Civil Interpretado.

R. Serv. públ., Brasília, 108 (3) set./dez. 1973 
ao patrimônio, à renda, e aos serviços vinculados às suas finalidades essenciais ou dela decorrentes" privilégios concedidos aos Estados, Distrito Federal e Municípios. Outra característica diferenciadora é a da necessidade do registro da escritura de constituição das empresas públicas e sociedades de economia mista, enquanto a autarquia, tendo em vista a sua natureza de direito público, independe desta formalidade, regulando-se pela lei que a instituiu.

Atente-se também para a norma constitucional do $\S 2 .^{\circ}$ do artigo 170:

"Na exploração, pelo Estado, da atividade econômica, as empresas públicas e as sociedades de economia mista reger-se-ão pelas normas aplicáveis às empresas privadas, inclusive quanto ao direito do trabalho e das obrigações." (grifamos).

A não inclusão das autarquias no dispositivo acima não nos deixa margem de dúvida quanto à distinção entre estas e as entidades paraestatis, recebendo estas últimas incumbências de execução de serviços públicos e de utiuidade pública de natureza comercial e industrial, perseguindo, portanto, a obtenção de lucros.

Modernamente o Direito Administrativo tem admitido a figura das fundações instituídas por lei, também sujeitas às normas de direito privado (Código Civil, art. 16, I, e 24 a 30), visto a transformação que vem se processando nas formas de sua organização, constituição de seu patimônio, e nomeação de seus dirigentes, passando a exercer atividades de interesse geral. "Com isto passaram a constituir uma nova espécie do gênero paraestatal. Esse amoldamento das fundações culturais a entes paraestatais visa conciliar o caráter privado da instituição com as atividades de interesse público que lhe são cometidas, no setor da pesquisa, da educação e do ensino, que o Estado chamou a si, sem dispensar, todavia, a iniciativa particular e os recursos individuais.

Apesar da reforma administrativa federal não incluir as fundações entre os órgãos da administração indireta, apenas subordinando-as ao controle e à supervisão administrativas (art. $3^{\circ}$, Decreto-lei 900 , de 29.9.1969), a Lei $n .^{\circ} 4.545$, de 10.12.1964, contrariamente assim o faz, mencionando-as no rol dos seus entes autônomos de administração (art. $3 .{ }^{\circ}, \mathrm{n} .^{\circ}$ II). 
A nova sede da República, apesar de seus treze anos de existência, graças à ação enérgica e esperançosa de seus administradores, aliada à tenacidade e ao espírito empreendedor dos brasilienses, dispõe de uma máquina administrativa apta a acompanhar e a colaborar na grande obra que se habitou chamar de "O MILAGRE BRASILEIRO". As multifárias atividades da administração do Distrito Federal acham-se divididas, compondo uma grande constelação de entidades incumbidas de atuarem em todos os setores: indústria, comércio, agricultura, rede bancária, ensino, cultura, serviços públicos e de utilidade pública, criados ou cuja constituição foi autorizada pelas Leis n.'s 2.874, de 19 de setembro de 1956 - dispõe sobre a mudança da Capital Federal - 3.751, de 21 de abril de 1960 - Organização Administrativa do Distrito Federal -4.545 , de 10 de dezembro de 1964 - Reestruturação Administrativa do Distrito Federal decreto-lei n. 524 , de 8 de abril de 1969 - Constitui a Companhia de Águas e Esgotos de Brasília - CAESB, 5.691, de 10 de agosto de 1971 - Constitui a Central de Abastecimento de Brasília S/A. - CENABRA, 5.861, de 12 de dezembro de 1972 - Altera o objeto da Companhia Urbanizadora da Nova Capital do Brasil e autoriza a Constituição da Companhia Imobiliária de Brasília - TERRACAP.

Fastidiosa será a enumeração das autarquias, empresas públicas, sociedades de economia mista e fundações, classificando-as quanto ao seu conceito, à sua natureza jurídica e setor de atividades.

No entanto, não poderemos nos furtar de fazê-lo, tendo em vista o objetivo deste trabalho.

\section{AUTARQUIA:}

Departamento de Estradas de Rodagem

Natureza Jurídica: Pessoa Jurídica de Direito Público.

Objetivos: Exercer atividades no setor rodoviário, colaborar com o DNER nos limites do-Distrito Federal e construir obras rodoviárias. 


\section{EMPRESAS PÚBLICAS:}

Sociedade de Abastecimento de Brasília

Natureza Jurídica: Pessoa Jurídica de Direito Privado

Objetivos: A exploração comercial e industrial de gêneros alimentícios em geral e produtos de consumo e uso doméstico, bem como similares em natureza, beneficiados e industrializados, com a finalidade de abastecer o Distrito Federal pela organização da estocagem e distribuição de tais gêneros.

Companhia de Água e Esgotos de Brasília Natureza Jurídica: Pessoa Jurídica de Direito Privado.

Objetivos: Executar, operar, manter e explorar os sistemas de abastecimento d'água; coleta de esgotos sanitários e controle das bacias hidrográficas de abastecimento.

Sociedade de Habitação de Interesse Social Natureza Jurídica: Pessoa Jurídica de Direito Privado.

Objetivos: Facilitar a aquisição de moradia a pessoas de reduzido poder aquisitivo.

Sociedade de Transportes Coletivos de Brasília Natureza Jurídica: Pessoa Jurídica de Direito Privado.

Objetivos: Explorar os serviços de transportes coletivos e de táxis.

Companhia Urbanizadora da Nova Capital do Brasil Natureza Jurídica: Pessoa Jurídica de Direito Privado Objetivos: Construção e execução de obras e serviços de urbanização.

Companhia Imobiliária de Brasília - TERRACAP Natureza Jurídica: Pessoa Jurídica de Direito Privado.

Objetivos: Incorporação, oneração ou alienação de bens. 
SOCIEDADES DE ECONOMIA MISTA:

Banco Regional de Brasília

Natureza Jurídica: Pessoa Jurídica de Direito Privado.

Objetivos: Realização de operações bancárias com vistas ao desenvolvimento geo-econômico do Distrito Federal.

Companhia do Desenvolvimento do Planalto Central CODEPLAN

Natureza Jurídica: Pessoa Jurídica de Direito Privado.

Objetivos: Promover o desenvolvimento sócio-econômico do Distrito Federal, fomentando a produção em todas as suas formas, através de estudos, pesquisas, coordenação, assistência técnica e assistência financeira.

Companhia de Telecomunicações de Brasília - COTELB Natureza Jurídica: Pessoa Jurídica de Direito Privado.

Objetivos: Administrar, nos termos da concessão outorgada, os serviços telefônicos.

COMPANHIA DE ELETRICIDADE DE BRASÍLIA - CEB

Natureza Jurídica: Pessoa Jurídica de Direito Privado.

Objetivos: Proceder estudos, projetos e a construção e operação de usinas e linhas de distribuição de energia elétrica.

Central de Abastecimento de Brasília - CENABRA Natureza Jurídica: Pessoa Jurídica de Direito Privado.

Objetivos: Polarizar e coordenar o abastecimento de gêneros alimentícios. 


\section{FUNDAÇÕES:}

Fundação Cultural do Distrito Federal

Natureza Jurídica: Pessoa Jurídica de Direito Privado.

Objetivos: Criação de centros artísticos, científicos e culturais, promoção de atividades artísticas e científicas, incremento do turismo em colaboração com o DETUR.

Fundação Educacional do Distrito Federal

Natureza Jurídica: Pessoa Jurídica de Direito Privado.

Objetivos: Prestar assistência educacional nos níveis elementar e médio.

Fundação Hospitalar do Distrito Federal

Natureza Jurídica: Pessoa Jurídica de Direito Privado.

Objetivos: Prestar assistência médico-hospitalar à população do DF.

Fundação do Serviço Social do Distrito Federal

Natureza Jurídica: Pessoa Jurídica de Direito Privado.

Objetivos: Promover e executar programas sociais, criando unidades ou serviços assistenciais.

\section{Fundação Zoobotânica do Distrito Federal}

Natureza Jurídica: Pessoa Jurídica de Direito Privado.

Objetivos: Estabelecer Parques Zoobotânicos no DF.

A diversidade dos órgãos e a enorme especialização das funções administrativas integrantes da complexa estrutura do Distrito Federal, porém, não acarretará a massificação e a coisificação do homem, em face de seus fundamentos filosóficos, o homem como fator essencial da máquina administrativa utilizada como meio e dominada pela inteligência humana, para alcançar o bem-estar e o progresso da coletividade.

Uma organização programada para servir ao homem, como ser moral, como ser político, como ser econômico, como ser 
social, sem qualquer restrição à sua força criadora, em que the são outorgadas maiores parcelas de autoridade e de responsabilidade haverá de produzir uma sociedade equilibrada, eficiente e desenvolvida.

São palavras de HENRY KISSINGER, o famoso estadista e professor norte-americano: "A estabilidade de uma sociedade depende de sua capacidade de organização, que lhe permite reagir mecanicamente a problemas comuns e utilizar os seus recursos com os melhores resultados. A grandeza de uma sociedade decorre de sua disposição de conquistar novas áreas, fora dos limites da rotina. Sem organização, cada problema representa um caso especial. Sem inspiração, a sociedade irá estagnar. Perderá a capacidade de adaptar-se a novas circunstâncias ou de gerar novos objetivos".

"A sociedade deve sua vitalidade à capacidade de encontrar o equilíbrio entre os requisitos da organização e a necessidade de inspiração. Ênfase excessiva em organização conduz à burocratização e ao debilitamento da imaginação. Excessiva ênfase em inspiração produz um tour de force sem continuidade ou estabilidade organizativa." 25

25) HENRY KISSINGER - "Armas Nucleares e Politica Externa". Apud Aula Inaugural da Escola Superior de Guerra proferida em 8 de março de 1972, pelo Ministro do Planejamento e Coordenação-Geral, João Paulo dos Reis Velloso.

R. Serv. públ., Brasília, 108 (3) set./dez. 1973 